\title{
Carbon sequestration by patch fertilization: A comprehensive assessment using coupled physical-ecological-biogeochemical models
}

\author{
Grant DE-FG02-00ER63009 \\ DOE Office of Biological and Environmental Research
}

\author{
FINAL REPORT \\ PRINCETON UNIVERSITY \\ Jorge L. Sarmiento, PI \\ Anand Gnanadesikan, Co-I \\ UNIVERSITY OF CALIFORNIA, LOS ANGELES \\ Nicolas Gruber, PI
}

\section{Overview}

This final report summarizes research undertaken collaboratively between Princeton University, the NOAA Geophysical Fluid Dynamics Laboratory on the Princeton University campus, the State University of New York at Stony Brook, and the University of California, Los Angeles between September 1, 2000, and November 30, 2006, to do

fundamental research on ocean iron fertilization as a means to enhance the net oceanic uptake of $\mathrm{CO}_{2}$ from the atmosphere.

The approach we proposed was to develop and apply a suite of coupled physical-ecologicalbiogeochemical models in order to

(i) determine to what extent enhanced carbon fixation from iron fertilization will lead to an increase in the oceanic uptake of atmospheric $\mathrm{CO}_{2}$ and how long this carbon will remain sequestered (efficiency), and

(ii) examine the changes in ocean ecology and natural biogeochemical cycles resulting from iron fertilization (consequences).

The award was funded in two separate three-year installments:

- September 1, 2000 to November 30, 2003, for a project entitled "Ocean carbon sequestration by fertilization: An integrated biogeochemical assessment.” A final report was submitted for this at the end of 2003 and is included here as Appendix 1.

- December 1, 2003 to November 30, 2006, for a follow-on project under the same grant number entitled "Carbon sequestration by patch fertilization: A comprehensive assessment using coupled physical-ecological-biogeochemical models."

This report focuses primarily on the progress we made during the second period of funding subsequent to the work reported on in Appendix 1.

When we began this project, we were thinking almost exclusively in terms of long-term fertilization over large regions of the ocean such as the Southern Ocean, with much of our focus being on how ocean circulation and biogeochemical cycling would interact to control the response to a given fertilization scenario. Our research on these types of scenarios, which was carried out largely during the first three years of our project, led to several major new insights on the interaction between ocean biogeochemistry and circulation. This work, which is described in 
the following Section II on "Large scale fertilization," has continued to appear in the literature over the past few years, including two high visibility papers in Nature.

Early on in the first three years of our project, it became clear that small "patch-scale" fertilizations over limited regions of order $100 \mathrm{~km}$ diameter were much more likely than large scale fertilization, and we carried out a series of idealized patch fertilization simulations reported on in Gnanadesikan et al. (2003). Based on this paper and other results we had obtained by the end of our first three-year grant, we identified a number of important issues that needed to be addressed in the second three-year period of this grant. Section III on "patch fertilization" discusses the major findings of this phase of our research, which is described in two major manuscripts that will be submitted for publication in the near future. This research makes use of new more realistic ocean ecosystem and iron cycling models than our first paper on this topic. We have several major new insights into what controls the efficiency of iron fertilization in the ocean.

Section IV on "model development" summarizes a set of papers describing the progress that we made on improving the ecosystem models we use for our iron fertilization simulations.

\section{Large scale fertilization}

\section{Publications (Dec. 1, 2003 to Nov. 30, 2006)}

Gnanadesikan, A., J. P. Dunne, R. M. Key, K. Matsumoto, J. L. Sarmiento, R. D. Slater, and P, S. Swathi, 2004. Oceanic ventilation and biogeochemical cycling: Understanding the physical mechanisms that produce realistic distributions of tracers and productivity. Global Biogeochem. Cycles, 18, GB4010, doi:10.1029/2003GB002097.

Hiscock, M.R., Sarmiento, J.L., Sweeney, C., in preparation. Modeling a basin scale iron addition in the Southern Ocean.

Marinov, I., 2005. Controls on the air-sea balance of carbon dioxide, PhD thesis, Atmospheric and Oceanic Sciences Program, Princeton University.

Marinov, I. A. Gnanadesikan, J. R. Toggweiler, and J. L. Sarmiento, 2006. The Southern Ocean biogeochemical divide. Nature, 441: 964-967.

Marinov, I., A. Gnanadesikan, J. L. Sarmiento, J. R. Toggweiler, M. Follows and B.K. Mignone, submitted. Impact of oceanic circulation on biological carbon storage in the ocean and atmospheric $\mathrm{pCO}_{2}$. (Global Biogeochem. Cycles)

Mignone, B. K., A. Gnanadesikan, J. L. Sarmiento, R. D. Slater, 2006. Central role of southern hemisphere winds and eddies in modulating the oceanic uptake of anthropogenic carbon. Geophys. Res. Lett., 33, L01604, doi:10.1029/2005GL024464.

Najjar, R. G., X. Jin, F. Louanchi, O. Aumont, K. Caldeira, S. C. Doney, J.-C. Dutay, M. Follows, G. M. Kay, E. Maier-Reimer, R. J. Matear, K. Matsumoto, A. Mouchet, J. C. Orr, G. K. Plattner, J. L. Sarmiento, M. F. Weirig, Y. Yamanaka, and A. Yool, in press. Impact of circulation on export production, dissolved organic matter and dissolved oxygen in the ocean: Results from OCMIP-2. (Global Biogeochem. Cycles).

Nevison, C.D., R. F. Keeling, R. F. Weiss, B. N. Popp, X. Jin, P. J. Fraser, L. W. Porter and P. G. Hess, 2005. Southern Ocean ventilation inferred from seasonal cycles of atmospheric $\mathrm{N}_{2} \mathrm{O}$ and $\mathrm{O}_{2} / \mathrm{N}_{2}$ at Cape Grim, Tasmania. Tellus B, vol. 57, 218-119.

Rodgers, K.B., O. Aumont, C. Menkes. and T. Gorgues, submitted. Decadal variations in equatorial Pacific ecosystems and ferrocline/pycnocline decoupling. (Global Biogeochem. Cycles).

Sarmiento, J. L., N. Gruber, M. A. Brzezinski, and J. P. Dunne, 2004. High latitude controls of the global nutricline and low latitude biological productivity. Nature, 427: 56-60.

Sarmiento, J. L., J. Simeon, and A. Gnanadesikan, in preparation-b. Sub-Antarctic Mode Water pathways and nutrients. 


\section{Summary of main findings}

Work carried on under this activity focused on understanding the fundamental processes that determine the efficiency and consequences of iron fertilization. In particular, we focused on understanding the processes controlling the biological pump of carbon involving the sinking of organic matter into the deep ocean. Carbon sequestration through iron fertilization ultimately relies on taking nutrients which were previously not associated with carbon (so-called "preformed" nutrients) and causing them to participate in the biological pump. We also looked at how climate change (in particular changes in wind stress) would affect carbon fluxes. Such changes would confound efforts to attribute changes in the biological pump, and would therefore need to be taken into account were claims to be made about the efficiency of circulation.

A significant part of this activity involved examining the role of ocean circulation in determining how the biological pump works. As discussed in Gnanadesikan et al. (2004) and Najjar et al. (in press) the net flux of biogenic carbon from the surface ocean to the deep ocean depends sensitively on the background circulation, with relatively realistic models ranging over a factor of about 2. The key processes determining the magnitude of this flux are mixing (both horizontal and vertical) and Southern Ocean winds. Models with higher levels of mixing also have significantly higher biological fluxes.

A larger biological flux out of the mixed layer does not, however, imply that more carbon is in fact stored in the ocean. Marinov (2005) and Marinov et al. (subm.) demonstrate this by looking across a range of circulation models. Increasing vertical and horizontal mixing within these models results in a greater fraction of the deep ocean being ventilated from the Southern Ocean, a region with high preformed nutrients (and thus a region in which the present (i.e., unperturbed) biological pump is not effective at sequestering carbon dioxide). As a result, the models with a large carbon export actually store less carbon in the deep ocean. Characterizing the level of ventilation within the Southern Ocean and the locations where it occurs is thus very important for both describing the present-day biological pump and for identifying regions where it is particularly susceptible to fertilization. The paper by Nevison et al. (2005) represents a step in this direction.

That the details of Southern Ocean ventilation matter is demonstrated by work reported in Marinov et al. (2006), which shows that atmospheric $\mathrm{CO}_{2}$ is controlled primarily by the biological pump and circulation in the Antarctic deep-water formation region. This work also highlights the crucial role of the convective regions such as the Weddell Sea in setting the air-sea $\mathrm{CO}_{2}$ balance. This is important as it suggests that some of the regions in which fertilization might have the largest impact on atmospheric carbon dioxide are among the most inaccessible. Additionally, the fact that the relationship between particle export and carbon drawdown is highly dependent on location illustrates the difficulty in properly crediting carbon sequestration resulting from fertilization.

Because of the importance of the Southern Ocean in controlling the air-sea balance of $\mathrm{CO}_{2}$, thereby also being the location where iron fertilization could have the largest effect, we have attempted to understand the biogeochemical response to iron fertilization in this region in more detail. In particular, we have attempted to understand the relative roles of light and iron limitation in making this a high nutrient low chlorophyll region. Light is clearly an important limiting factor in the wintertime due to the sun angle, but we have shown that it also appears to be an important factor in the summer time due to the deep mixed layers predominant over much of this region even in summer (Hiscock et al., in preparation). We have done this using a 
combination of information from in situ iron-enrichment measurements and climatological data to develop a simple model of an iron-replete Southern Ocean. Results from this work suggest that, indeed, basin scale iron addition draws down more nitrate than iron fertilization experiments. However, basin scale Fe-addition fails to deplete nitrate concentrations entirely. It appears that in iron-replete conditions the Southern Ocean is ultimately light limited. Further experiments in which seasonal North Atlantic mixed layer depths are simulated in the Southern Ocean showed that decreasing mixed layer depth has a greater effect on nitrate utilization than adding iron does, and that a complete depletion requires both a shallower mixed layer and iron addition.

Marinov et al. (2006) also highlight the role of the Subantarctic Mode and Intermediate Water in the global biological pump, demonstrating that these regions account for most of the preformed nutrients that make it to the surface throughout most of the world ocean. This is in agreement with the observational study of the relationship between silicate and nitrate reported in Sarmiento et al. (2004). Thus an important consequence of fertilizing the Subantarctic zone is to "borrow" productivity at some later time from the tropical oceans. This illustrates the important policy implications surrounding the issue of fertilization.

Changes due to proposed fertilization would also have to be evaluated in the context of a changing climate. Three studies at least partially supported under this grant have considered such impacts. Sarmiento et al. (in preparation-b) are currently examining how changes due to global warming would affect the biological pump by changing the rate of formation of mode and intermediate waters. This work seems to indicate that the rate of formation is not significantly changed in coupled climate models, in part because the winds become stronger. This in turn means that global warming will not "shield" the tropics from the consequences of Southern Ocean fertilization. The increase in Southern Ocean winds is also predicted to lead to an increased uptake of anthropogenic carbon dioxide, at least within the Southern Ocean (Mignone et al., 2006).

A final study (Rodgers et al., subm.) focuses on whether the Equatorial Pacific is likely to become more or less favorable for fertilization under climate change- using the 1976/1977 regime shift as simulated in the French ORCA/PISCES model as a test case. This paper demonstrates that a weakening in wind stress (such as is predicted to occur under global warming) has a disproportionate effect on iron and chlorophyll, substantially reducing the iron/nitrate ratio in upwelling waters. The reason is that (at least within this model) most of the iron in these waters is supplied from the continental shelf off of New Guinea, so that a shallowing of the pycnocline in this region decouples the ferrocline from the nitricline.

\section{Patch fertilization}

Publications (Dec. 1, 2003 to Nov. 30, 2006)

Jin, X., N. Gruber, H. Frenzel, S. C. Doney, and J. C. McWilliams, in preparation. The impact on atmospheric $\mathrm{CO}_{2}$ of iron fertilization induced changes in the ocean's biological pump.

Sarmiento, J. L., R. D. Slater, M. E. Maltrud, A. Gnanadesikan, and J. Dunne, in preparation-a. Iron fertilization models revisited.

\section{Summary of main findings}

A measure of the overall impact of the addition of iron on atmospheric $\mathrm{CO}_{2}$ is the ratio of $\mathrm{CO}_{2}$ removal-to-iron added, which reflects how much additional $\mathrm{CO}_{2}$ is taken up from the 
atmosphere for a given amount of iron added to the ocean. This fertilization ratio can be split into a component that reflects how much $\mathrm{CO}_{2}$ is taken up from the atmosphere per unit change in biological export (termed the atmospheric uptake efficiency), and into a biological iron utilization ratio that reflects how a given amount of added iron stimulates the biological export of carbon (termed the iron utilization ratio). By definition, the product of the atmospheric uptake efficiency and the biological iron utilization ratio is the fertilization ratio.

As summarized in our 2003 summary report (Appendix 1), our short-term patchfertilization scenarios suggested that the efficiency of small-scale iron fertilization scenarios, i.e., the fraction of increased export production that comes from the atmosphere, was likely to be extremely low ( 2\% after 100 years; Gnanadesikan et al., 2003). An important caveat is that the biogeochemistry model that was used for these simulations is an extremely simple diagnostic model based on forcing surface nutrients back towards observations, or to 0 in the case of the nutrient depletion scenarios. Furthermore, there was no explicit model of the iron cycle. A major goal of the second three year period of this grant was thus to develop a new set of ecosystem and iron cycle models and to use these in a new set of simulations to test the findings of the Gnanadesikan et al. (2003) study.

While this model development work was going on (see discussion in Section IV), Sarmiento received separate funding from DOE to organize an Ocean Carbon Sequestration Research Workshop held in May 2005 at which a group of DOE funded principal investigators met in order to discuss progress on ocean carbon sequestration science. At that meeting, Prof. John Marshall of MIT presented a new study subsequently published by Dutkiewicz et al. (2006), which found much greater efficiencies of atmospheric drawdown than Gnanadesikan et al. (2003). They also determined that the highest uptake of atmospheric $\mathrm{CO}_{2}$ occurred when iron was added in the equatorial Pacific, differing dramatically from earlier macronutrient manipulation studies showing that the Southern Ocean gave the highest $\mathrm{CO}_{2}$ uptake (e.g., Sarmiento and Orr, 1991). This led to the organization of an Iron Fertilization Model Intercomparison Project (IFMIP), which has served as a focal point for our research during the period since the meeting was held.

IFMIP was designed to investigate the potential of iron fertilization to remove atmospheric $\mathrm{CO}_{2}$ using models that fully resolve the marine iron cycle and include more complex (and more realistic) representations of the marine biosphere than previously employed. This has permitted us to overcome an important limitation of the prior studies in that it is possible now to determine not only the atmospheric uptake efficiency, but also the biological iron utilization ratio, and hence the carbon-to-iron fertilization ratio. The results of IFMIP, which has now been completed, are reported on in papers by Jin et al. (in preparation) and Sarmiento et al. (in preparation-a), which are almost ready to submit. One of the most important findings of IFMIP is the high atmospheric uptake efficiency. We have investigated the factors that contribute to this new finding.

In Jin et al., the UCLA component of our group carried out a series of sensitivity studies to examine the processes that determine how the uptake of $\mathrm{CO}_{2}$ across the air-sea interface is related to the export of organic matter across the base of the euphotic zone. Atmospheric uptake efficiency, i.e., the amount of atmospheric $\mathrm{CO}_{2}$ draw-down per unit of biological export induced by iron fertilization, is a critical criterion to assess the impact of changes of the biological pump on atmospheric $\mathrm{CO}_{2}$, e.g., the feasibility, effectiveness with regard to lowering atmospheric $\mathrm{CO}_{2}$ using iron fertilization. Jin et al. used a Pacific Ocean setup of ROMS (the Regional Oceanic Modeling System) at an eddy-permitting resolution of 0.5 degrees, coupled with an 
ecosystem model, including three phytoplankton functional groups and multiple nutrient limitation (N, P, Si, Fe). We performed simulations with different patch sizes and fertilization durations to investigate the factors that control the uptake efficiency.

The Jin et al. study found very high atmospheric uptake efficiency for our standard patch iron fertilization, achieving $81 \%$ for a ten years duration of iron fertilization. This high efficiency was relatively insensitive to the iron addition patch size. We found that the main factor that controls the atmospheric uptake efficiency is the depth distribution within the euphotic zone where the stimulated export production occurs. The closer to the surface the dissolved inorganic carbon is taken from, the greater the faction of this that is replaced from the atmosphere, resulting in high uptake efficiencies. In the equatorial Pacific Ocean, we found that the uptake efficiency was proportional to the fraction of total stimulated net primary production that occurs in the top 10 meters.

In Sarmiento et al., the Princeton University and GFDL component of our group, together with Mat Maltrud of Los Alamos National Laboratory, analyze the biogeochemical model simulations in more detail and carry out a series of biogeochemical sensitivity studies in order to examine what processes specifically account for the differences between models and between regions. The sensitivity studies described here include how the response to iron fertilization is affected by: (1) the inclusion of an atmospheric reservoir (which the Dutkiewicz, et al. [2006] study did not); and (2) by iron biogeochemistry including (a) how much iron is added, (b) how effectively the ocean recycles iron, and (c) the time scale of iron fertilization. The conclusions are:

1. Contrary to Dutkiewicz, et al. [2006], we find the largest response in the Southern Ocean region with the Equatorial Pacific and other locations all being lower in both the biological export and atmospheric $\mathrm{CO}_{2}$ uptake. Our result is due to the high C:Fe uptake ratio. We believe that this difference in behavior between our analysis and that of Dutkiewicz, et al. [2006] is due primarily to the fact that their model is excessively light limited in the Southern Ocean.

2. The very high biological C:Fe uptake ratio of the Southern Ocean is driven in turn by the fact that this locations is unique in having both a high fraction of the added iron continuing to participate in biological production rather than being lost to deep waters where it is not available for reuse, and a high C:Fe ratio in the organic matter that is produced. No other location has both of these as high.

3. There is a very large loss of $\mathrm{CO}_{2}$ from the ocean when a realistic atmospheric reservoir is included (cf. Gnanadesikan, et al. [2003]). By the $100^{\text {th }}$ year of the IFMIP simulation, half of the $\mathrm{CO}_{2}$ that is absorbed by the model with no atmospheric reservoir is lost back to the atmosphere in the model with a realistic atmospheric reservoir. Thus the Dutkiewicz, et al. [2006] simulation gives twice as large a $\mathrm{CO}_{2}$ uptake as it should.

4. As might be expected, there is a very large sensitivity of the biological response to an iron addition when the iron is retained in the model than when it is used once and lost. The simulations with iron lost have a much smaller biological response. Interestingly, the physical efficiency is insensitive to whether the iron is retained or lost.

5. A final point we examined was whether additional iron could lead to depletion of nutrients during at least part of the year. Our results show that all the stations can be driven to 0 nitrate in the summer time, but only the Equatorial Pacific can be driven to 0 mean nitrate year around. In fact, in the Southern Ocean and Ross Sea, the nutrient 
concentration maximum recovers all the way to its wintertime maximum even in the 1000x case, testifying to the effectiveness of the circulation in returning nutrients to these two regions.

\section{Model development}

Publications (Dec. 1, 2003 to Nov. 30, 2006)

Armstrong, R.A. 2006. Optimality-based modeling of nitrogen allocation and photoacclimation in photosynthesis. Deep-Sea Research II 53:513-531.

Armstrong, R.A., submitted. Modeling size dependence of nutrient uptake: a Michaelis-form alternative to Aksnes and Egge. (Deep-Sea Research I)

Deutsch, C., J. L. Sarmiento, D. M. Sigman, N. Gruber, and J. P. Dunne, 2007. Spatial coupling of nitrogen inputs and losses in the ocean. Nature, 445: 163-167.

Dunne, J. P., R. A. Armstrong, A. Gnanadesikan, and J. L. Sarmiento, 2005. Empirical and mechanistic models for the particle export ratio. Global Biogeochem. Cycles, 19, GB4026, doi:10.1029/2004GB002390.

Dunne, J. P., J. L. Sarmiento, and A. Gnanadesikan, in press. A synthesis of global particle export from the surface ocean and cycling through the ocean interior and on the sea floor. (Global Biogeochem. Cycles)

Jin, X., N. Gruber, J. P. Dunne, J. L. Sarmiento, and R. A. Armstrong, 2006. Diagnosing the contribution of phytoplankton functional groups to the production and export of particulate organic carbon, $\mathrm{CaCO}_{3}$, and opal from global nutrient and alkalinity distributions. Global Biogeochem. Cycles, 20, GB2015, doi10.1029/2005GB002532.

\section{Summary of main findings}

The most important accomplishment of this period of our grant was the development and implementation of a new ecosystem and iron cycling model by co-investigator John Dunne of GFDL/NOAA with some assistance from Princeton University. Many of the basic concepts underlying the model owe their genesis to research by our collaborator Rob Armstrong of SUNY Stonybrook. This model was used for the iron fertilization simulations of Sarmiento et al. (in preparation), and is described therein. Some of the ideas that contributed to the model, and some of the observational analyses that were used in testing the model, are described in the papers by Deutsch et al. (2005), and Dunne et al. (2005 and in press). We summarize below additional accomplishments based on research that was carried out in order to improve the ecosystem model:

We have made considerable progress in developing our biogeochemistry/ecology models in the following aspects.

\section{1) Phytoplankton functional groups (Jin et al., 2006)}

We have used observations to diagnose the contribution of four main phytoplankton functional groups to the production and export of particulate organic carbon (POC), $\mathrm{CaCO}_{3}$ and opal by combining in a restoring approach global oceanic observations of nitrate, silicic acid and alkalinity with a simple size dependent ecological/biogeochemical model. In order to determine the robustness of our results, we employed three different variants of the ocean general circulation model (OGCM) required to transport and mix the nutrients and alkalinity into the 
upper ocean. These results are being used to inform the development of our ecosystem models. A brief description of our most important findings follows.

In our standard model, the global export of $\mathrm{CaCO}_{3}$ was diagnosed as $1.1 \mathrm{PgC} \mathrm{yr}^{-1}$ (range

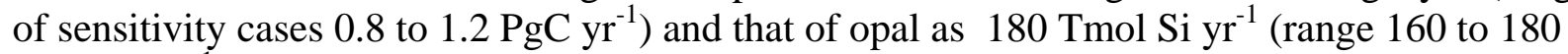
Tmol Si yr ${ }^{-1}$ ). $\mathrm{CaCO}_{3}$ export was found to have three maxima at approximately $40^{\circ} \mathrm{S}$, the equator, and around $40^{\circ} \mathrm{N}$. In contrast, the opal export was dominated by the Southern Ocean with a single maximum at around $60^{\circ} \mathrm{S}$. The molar export ratio of inorganic to organic carbon was diagnosed in our standard model to be about 0.09 (range 0.07 to 0.10 ) and found to be remarkably uniform spatially. The molar export ratio of opal to organic nitrogen varies substantially from values around 2 to 3 in the Southern Ocean south of $45^{\circ} \mathrm{S}$ to values below 0.5 throughout most of the rest of the ocean, except for the North Pacific.

Irrespective of which OGCM is used, large phytoplankton dominate the export of POC, with diatoms alone accounting for $40 \%$ of this export, while the contribution of coccolithophorids is only about $10 \%$. Small phytoplankton dominate net primary production (NPP) with a fraction of $\sim 70 \%$. Diatoms and coccolithophorids account for about $15 \%$ and less than $2 \%$ of NPP, respectively. These diagnosed contributions of the main phytoplankton functional groups to NPP are also robust across all OGCMs investigated. Correlation and regression analyses revealed that the variations in the relative contributions of diatoms and coccolithophorids to NPP can be predicted reasonably well on the basis of a few key parameters.

Our new results not only provide a basis for our new ecosystem model development, but also provide crucial information on functional groups that can be used as a firm basis to test models and lead to the development of improved models.

\section{2) Optimality-based modeling of nitrogen allocation and photoacclimation in photosynthesis (Armstrong, 2006)}

Only recently has it become widely recognized in the biogeochemistry modeling community that the taxonomic composition of planktonic ecosystems may play a key role in determining atmospheric $\mathrm{CO}_{2}$ (Moore et al. 2002a,b; Armstrong 2003a,b). This recognition implies that the ability to represent competition and exclusion among phytoplankton and zooplankton will be critical to predicting the response of the oceanic carbon cycle to environmental change (Totterdell et al. 1993; Armstrong 2003a,b). Models with such capabilities will of necessity be complicated, and will require accurate but simple representations of both growth and grazing. To achieve this predictive capability, models must be able to represent the characteristic physiology of each taxonomic group with reasonable fidelity; but in order to prevent a catastrophic inflation of parameter space, constraints on parameter values within taxa must also be developed.

While biochemistry and molecular biology provide the ultimate mechanistic basis for modeling, models based directly on molecular mechanisms are at present too detailed to be useful for biogeochemistry modeling. Instead, modeling of physiological processes using tradeoffs in resource allocation among competing physiological demands may produce models compact enough to be used in biogeochemistry.

Essentially all ecosystem models in ocean biogeochemistry use one of two strategies for modeling the interaction of light and nitrogen in photosynthesis. The first approach is based on Liebig's "Law of the Minimum;" in this model, photosynthetic rate is set by the "most limiting" factor, in this case either nitrogen or light. A second approach is to view limitation as a 
multiplicative process. A third, recently popular state-of-the-art model of light/nitrogen interaction, is that of Geider et al. (1998), which has a more complicated structure in which nitrogen limitation and temperature affect maximum photosynthetic rate through the dark reactions of photosynthesis, but do not affect photosynthetic rate at low light levels.

As part of their model, Geider et al. $(1996,1998)$ posit that the chlorophyll:carbon ratio $\theta^{C}$ is determined by a "chlorophyll $a$ synthesis regulation term." The mathematical form of this term is not derived from considerations of nitrogen allocation between light reactions and dark reactions, but rather by considering the redox state of photosystem II. In contrast, Armstrong (2006) produced a prediction of $\theta^{C}$ based on the idea that nitrogen should be allocated to light and dark reactions to maximize the rate of photosynthesis.

A full set of parameters was then estimated using data from Laws and Bannister (1980, 2004); these were in turn used to predict chlorophyll:carbon and nitrogen:carbon ratios as functions of growth rate. The Armstrong (2006) model was entered into the NASA-sponsored ppar3 competition among models of column productivity, where it performed exceptionally well despite not having been "tuned" for this purpose. Its performance suggests that the improved conceptualization of nitrogen:carbon and chlorophyll:carbon relationships in Armstrong (2006) outweighs any disadvantages from lack of tuning, and suggests that Armstrong (2006) may therefore provide a robust theoretical underpinning for a new generation of models of multiplenutrient limitation.

\section{3) Modeling size dependence of nutrient uptake: a Michaelis-form alternative to Aksnes and Egge (Armstrong, submitted)}

Munk and Riley (1952) were the first to explore mathematically the idea that nutrient supply to phytoplankton cells might be limited by diffusive or advective transport. Later, Pasciak and Gavis $(1974,1975)$ recognized that nutrient uptake is not limited solely by physical transport, but also by active biological transport across the cell surface; they therefore required that diffusive nutrient flux to the cell surface match the active transport flux across the cell membrane. Much later, Aksnes and Egge (1991) proposed a simplified model that included both cell-surface transport by porter proteins and diffusive transport through the surrounding medium, yet could be expressed in terms of standard Michaelis-Menton parameters. This model has been widely used for size-dependent modeling within the biogeochemistry modeling community. This manuscript shows that the Aksnes/Egge model has severe problems with representing sizedependence of nutrient uptake, especially at small cell sizes. An alternative Michaelis-form approximation is provided that may prove more useful to ecosystem and biogeochemistry modelers. Finally, a comparison was made with alterative models by fitting them to iron uptake data from Sunda and Huntsman (1997).

\section{Outreach (Sept. 1, 2000-Nov. 30, 2006)}

During the period of this grant, we wrote a series of overview papers related to the carbon cycle of the ocean that were informed by the research that was carried out as part of this project. None of these acknowledge a specific grant. These include:

- Boyd, P.W., T. Jickells, C. S. Law, S. Blain, E. A. Boyle, K. O. Buesseler, K. H. Coale, J. J. Cullen, H. J. W. de Baar, M. Follows, M. Harvey, C. Lancelot, M. Levasseur, N. P. J. Owens, R. Pollard, R. B. Rivkin, J. Sarmiento, V. Schoemann, V. Smetacek, S. Takeda, 
A. Tsuda, S. Turner, A. J. Watson, 2007. Mesoscale iron enrichment experiments 19932005: Synthesis and future directions. Science, 315: 612-617.

- $\quad$ Edmonds, J., F. Joos, N. Nakicenovic, R. G. Richels, and J. L. Sarmiento, 2004.

Scenarios, targets, gaps, and costs. In: The Global Carbon Cycle, ed. C. B. Field and M. R. Raupach, Island Press, Washington, D.C., pp. 77-102.

- Greenblatt, J. B., and J. L. Sarmiento, 2004. Variability and climate feedback mechanisms in ocean uptake of $\mathrm{CO}_{2}$. In: The Global Carbon Cycle, ed. C. B. Field and M. R. Raupach, Island Press, Washington, D.C., pp. 257-275.

- Gruber, N., P. Friedlingstein, C. B. Field, R. Valentini, M. Heimann, J. E. Richey, P. R. Lankao, E.-D. Schulze, and C.-T A. Chen, 2004. The vulnerability of the carbon cycle in the 21st Century: An assessment of carbon-climate-human interactions. In: The Global Carbon Cycle, ed. C. B. Field and M. R. Raupach, Island Press, Washington, D.C., pp. 45-76.

- Iglesias-Rodriquez, M. D., R. Armstrong, R. Feely, R. Hood, J. Kleypas, J. D. Milliman, C. Sabine, and J. Sarmiento, 2002. The marine calcium carbonate budget in a changing ocean. EOS Transactions, 83 (34): 365, 374-375.

- Marinov, I., and J. L. Sarmiento, 2004. The role of the oceans in the global carbon cycle: An overview. In: The Ocean Carbon Cycle and Climate, ed. M. Follows and T. Oguz, NATO ASI, Ankara, Turkey, Kluwer Academic Publishers, pp. 251-295.

- Sarmiento, J.L., and N. Gruber, 2002. Sinks for anthropogenic carbon, Physics Today, August 2002, pp 30-36.

In addition, we published a major textbook/research monograph on ocean biogeochemistry that summarizes the state of our understanding in a broad range of fields relevant to ocean carbon sequestration:

- Sarmiento, J. L., and N. Gruber, 2006. Ocean Biogeochemical Dynamics, Princeton University Press, Princeton. 503 pp.

\section{Summary}

As we noted in our previous three-year report given in Appendix 1, there are several critical scientific questions that have been identified as having the potential to be make-or-break issues for the proposed mechanism of carbon sequestration by iron fertilization. We used these as a template to summarize progress we had made during the first three years of our project. We use them here again to report on progress we made over the past three years of our project:

(1) If iron is added to the ocean, will export of organic carbon from the surface actually occur? Clearly, if no export occurs, then there will be no sequestration.

As we said in our previous report, the answer to this question will ultimately rest on in situ experiments. However, our new model studies using ecosystem and iron cycling models that have been developed with such experiments in mind all show enhanced organic carbon export occurring in response to iron fertilization, but with wide regional variations (Sarmiento et al., in preparation). In particular, the high latitude Southern Ocean shows very high C:Fe ratios in the organic matter that is exported from the surface due to the influence of high nitrate concentrations resulting from the way that $\mathrm{CO}_{2}$ uptake and Fe uptake are parameterized in the model. However, the overall uptake of $\mathrm{CO}_{2}$ also depends on the extent to which Fe is recycled within the ocean, and some of the Southern Ocean regions that lose iron to deep waters (e.g., in the Ross Sea) thus end out behaving similarly to low latitude regions where the C:Fe 
stoichiometry is much lower. These results point clearly to the importance of understanding clearly what processes control the C:Fe stoichiometery of exported organic matter as well as the cycling of iron.

(2) If iron fertilization does lead to export of organic carbon from the surface of the ocean, how much $\mathrm{CO}_{2}$ will actually be removed from the atmosphere? Even if carbon is removed from the surface of the ocean, this does not guarantee that there will be significant removal of $\mathrm{CO}_{2}$ from the atmosphere, since the $\mathrm{CO}_{2}$ may be supplied by a realignment of dissolved inorganic carbon within the ocean.

We have major new findings on this topic resulting from the studies of Jin et al. (in preparation) and Sarmiento et al. (in preparation). We have found much higher atmospheric uptake efficiencies than in previous studies and we have elucidated the processes that contribute to this. In Jin et al., we show that the atmospheric uptake efficiency is very sensitive to the depth at which the organic carbon uptake occurs, with the shallower removal that is characteristic of the new generation of more realistic ecosystem models giving much higher uptake efficiencies. In Sarmiento et al. we show how the retention of iron in the new ocean biogeochemistry models also contributes to the increased efficiency, although we also note that the behavior of the added iron in these models is speculative as we have no real information on this.

Conversely, in Sarmiento et al., we show that recent studies that have not included a realistic atmospheric reservoir overestimate the atmospheric uptake efficiencies by about a factor of 2 over a 100-year time scale. This is because there is a large-scale loss of $\mathrm{CO}_{2}$ from the ocean to the atmosphere that occurs in regions away from the area of iron fertilization due to the reversal of the air-sea $\mathrm{CO}_{2}$ gradient that results from the removal of atmospheric $\mathrm{CO}_{2}$ by iron fertilization. This perturbation effect occurs even when atmospheric $\mathrm{CO}_{2}$ is increasing due to anthropogenic emissions. This mechanism was clearly identified by Gnanadesikan et al. (2003), but its direct quantitative contribution has now been evaluated in detail.

(3) What is the time scale of any sequestration that occurs? If sequestered $\mathrm{CO}_{2}$ returns to the atmosphere on a relatively short time scale, iron fertilization will not contribute significantly to slowing the growth of atmospheric $\mathrm{CO}_{2}$.

We show in Sarmiento et al. (in preparation) that the time scale of the $\mathrm{CO}_{2}$ removal (and thus the overall efficiency of the fertilization) depends primarily on whether iron is retained in the ocean after the fertilization occurs. If iron is NOT retained, the excess carbon removed from the surface by the fertilization quickly returns to the surface and escapes back to the atmosphere (cf. Gnanadesikan et al., 2003). In our IFMIP simulation with continuous iron addition over a period of 100 years, the removal time of iron is slow enough that $60 \%$ of the iron added is still in the water column after 100 years. If the added iron had been lost immediately after being utilized once, rather than being slowly scavenged, the overall atmospheric uptake efficiency relative to iron addition would drop to $\sim 10 \%$ of its original value in most places examined.

(4) Can the magnitude of sequestration be verified? If verification is extremely difficult or impossible, this option is likely to be viewed less favorably.

We examined this issue in some detail in Gnanadesikan et al. (2003) and discuss our 
conclusions on page 10 of Appendix 1. An update of this discussion will be given in Sarmiento et al. (in preparation), where our conclusion will be the same as before, that verification would be extremely challenging.

(5) What unintended consequences might there be from fertilizing the ocean with iron? If these are severe enough, they will have a significant impact on policy decisions.

The two major unintended consequences that we have investigated are the potential for long-term reduction in biological production as nutrients are removed from the surface and sequestered at depth (Gnanadesikan et al., 2003; Sarmiento et al., 2004; and Marinov et al., 2005), and a potentially large production of nitrous oxide, a potent greenhouse gas that may counteract much of the effect of any $\mathrm{CO}_{2}$ removal that is achieved by a given fertilization event (Jin and Gruber, 2003).

\section{Graduate students and postdoctoral researchers trained (Sept. 1, 2000-Nov. 30, 2006)}

\section{Graduate students:}

- Dr. Curtis Deutsch, PhD awarded by Princeton University in 2003, subsequently a PostDoc at the University of Washington and now a professor at UCLA.

- Dr. Irina Marinov, PhD awarded by Princeton University in 2005, subsequently a PostDoc at MIT and now a Post-Doc at Woods Hole Oceanographic Institution.

\section{Post-docs:}

- Dr. John Dunne, Post-Doc at Princeton University, now on the research staff at GFDL/NOAA

- Dr. Michael Hiscock, Post-Doc at Princeton University

- Dr. Xin Jin, Post-Doc at UCLA.

\section{Publications supported by this grant}

\section{Book}

Sarmiento, J. L., and N. Gruber, 2006. Ocean Biogeochemical Dynamics, Princeton University Press, Princeton. 503 pp.

\section{Journal and book articles}

Sept. 1, 2000-Nov. 30, 2003 (published only; see Appendix 1)

Deutsch, C., 2003. Biogeochemical constraints on the modern and glacial oceanic nitrogen cycle. Ph.D. Thesis, Princeton University, Princeton, NJ.

Gnanadesikan, A., J. L. Sarmiento, and R. D. Slater, 2003. Effects of patchy ocean fertilization on atmospheric carbon dioxide and biological production. Global Biogeochem. Cycles, 17 (2), doi: 10.1029/2002GB001940.

Iglesias-Rodriquez, M. D., R. Armstrong, R. Feely, R. Hood, J. Kleypas, J. D. Milliman, C. Sabine, and J. Sarmiento, 2002. The marine calcium carbonate budget in a changing ocean. EOS Transactions, 83 (34): 365, 374-375.

Sarmiento, J. L., J. Dunne, A. Gnanadesikan, R. M. Key, K. Matsumoto, and R. Slater, 2002. A new estimate of the $\mathrm{CaCO}_{3}$ to organic carbon export ratio. Global Biogeochem. Cycles, 16 (4), 1107, doi:10.1029/2002GB001919. 
Sarmiento, J.L., and N. Gruber, 2002. Sinks for anthropogenic carbon, Physics Today, August 2002, pp 30-36.

Dec. 1, 2003-Nov. 30, 2006 (published, in press, and in preparation)

Armstrong, R.A. 2006. Optimality-based modeling of nitrogen allocation and photoacclimation in photosynthesis. Deep-Sea Research II 53:513-531.

Armstrong, R.A., submitted. Modeling size dependence of nutrient uptake: a Michaelis-form alternative to Aksnes and Egge. (Deep-Sea Research I)

Boyd, P.W., T. Jickells, C. S. Law, S. Blain, E. A. Boyle, K. O. Buesseler, K. H. Coale, J. J. Cullen, H. J. W. de Baar, M. Follows, M. Harvey, C. Lancelot, M. Levasseur, N. P. J. Owens, R. Pollard, R. B. Rivkin, J. Sarmiento, V. Schoemann, V. Smetacek, S. Takeda, A. Tsuda, S. Turner, A. J. Watson, 2007. Mesoscale iron enrichment experiments 1993-2005: Synthesis and future directions. Science, 315: 612-617.

Deutsch, C., J. L. Sarmiento, D. M. Sigman, N. Gruber, and J. P. Dunne, 2007. Spatial coupling of nitrogen inputs and losses in the ocean. Nature, 445: 163-167.

Dunne, J. P., R. A. Armstrong, A. Gnanadesikan, and J. L. Sarmiento, 2005. Empirical and mechanistic models for the particle export ratio. Global Biogeochem. Cycles, 19, GB4026, doi:10.1029/2004GB002390.

Dunne, J. P., J. L. Sarmiento, and A. Gnanadesikan, in press. A synthesis of global particle export from the surface ocean and cycling through the ocean interior and on the sea floor. (Global Biogeochem. Cycles)

Edmonds, J., F. Joos, N. Nakicenovic, R. G. Richels, and J. L. Sarmiento, 2004. Scenarios, targets, gaps, and costs. In: The Global Carbon Cycle, ed. C. B. Field and M. R. Raupach, Island Press, Washington, D.C., pp. 77-102.

Gnanadesikan, A., J. P. Dunne, R. M. Key, K. Matsumoto, J. L. Sarmiento, R. D. Slater, and P, S. Swathi, 2004. Oceanic ventilation and biogeochemical cycling: Understanding the physical mechanisms that produce realistic distributions of tracers and productivity. Global Biogeochem. Cycles, 18, GB4010, doi:10.1029/2003GB002097.

Greenblatt, J. B., and J. L. Sarmiento, 2004. Variability and climate feedback mechanisms in ocean uptake of $\mathrm{CO}_{2}$. In: The Global Carbon Cycle, ed. C. B. Field and M. R. Raupach, Island Press, Washington, D.C., pp. 257-275.

Gruber, N., P. Friedlingstein, C. B. Field, R. Valentini, M. Heimann, J. E. Richey, P. R. Lankao, E.-D. Schulze, and C.-T A. Chen, 2004. The vulnerability of the carbon cycle in the 21st Century: An assessment of carbon-climate-human interactions. In: The Global Carbon Cycle, ed. C. B. Field and M. R. Raupach, Island Press, Washington, D.C., pp. 45-76.

Hiscock, M.R., Sarmiento, J.L., Sweeney, C., in preparation. Modeling a basin scale iron addition in the Southern Ocean.

Jin, X., N. Gruber, H. Frenzel, S. C. Doney, and J. C. McWilliams, in preparation. The impact on atmospheric $\mathrm{CO}_{2}$ of iron fertilization induced changes in the ocean's biological pump.

Jin, X. and N. Gruber, 2003, Offsetting the radiative benefit of ocean iron fertilization by enhancing $\mathrm{N}_{2} \mathrm{O}$ emissions. Geophysical Research Letters, 30 (24) doi:10.1029/2003GL018458.

Jin, X., N. Gruber, J. P. Dunne, J. L. Sarmiento, and R. A. Armstrong, 2006. Diagnosing the contribution of phytoplankton functional groups to the production and export of particulate organic carbon, $\mathrm{CaCO}_{3}$, and opal from global nutrient and alkalinity distributions. Global Biogeochem. Cycles, 20, GB2015, doi10.1029/2005GB002532.

Marinov, I., 2005. Controls on the air-sea balance of carbon dioxide, PhD thesis, Atmospheric and Oceanic Sciences Program, Princeton University.

Marinov, I., M. Follows, A. Gnanadesikan, R.D. Slater and J. L. Sarmiento, in preparation. What controls the atmospheric $\mathrm{CO}_{2}$ response to surface nutrient depletion ?.

Marinov, I. A. Gnanadesikan, J. R. Toggweiler, and J. L. Sarmiento, 2006. The Southern Ocean biogeochemical divide. Nature, 441: 964-967. 
Marinov, I., A. Gnanadesikan, J. L. Sarmiento, J. R. Toggweiler, M. Follows and B.K. Mignone, submitted. Impact of oceanic circulation on biological carbon storage in the ocean and atmospheric $\mathrm{pCO}_{2}$. (Global Biogeochem. Cycles)

Marinov, I., and J. L. Sarmiento, 2004. The role of the oceans in the global carbon cycle: An overview. In: The Ocean Carbon Cycle and Climate, ed. M. Follows and T. Oguz, NATO ASI, Ankara, Turkey, Kluwer Academic Publishers, pp. 251-295.

Mignone, B. K., A. Gnanadesikan, J. L. Sarmiento, R. D. Slater, 2006. Central role of southern hemisphere winds and eddies in modulating the oceanic uptake of anthropogenic carbon. Geophys. Res. Lett., 33, L01604, doi:10.1029/2005GL024464.

Najjar, R. G., X. Jin, F. Louanchi, O. Aumont, K. Caldeira, S. C. Doney, J.-C. Dutay, M. Follows, G. M. Kay, E. Maier-Reimer, R. J. Matear, K. Matsumoto, A. Mouchet, J. C. Orr, G. K. Plattner, J. L. Sarmiento, M. F. Weirig, Y. Yamanaka, and A. Yool, in press. Impact of circulation on export production, dissolved organic matter and dissolved oxygen in the ocean: Results from OCMIP-2. (Global Biogeochem. Cycles).

Nevison, C.D., R. F. Keeling, R. F. Weiss, B. N. Popp, X. Jin, P. J. Fraser, L. W. Porter and P. G. Hess, 2005. Southern Ocean ventilation inferred from seasonal cycles of atmospheric $\mathrm{N}_{2} \mathrm{O}$ and $\mathrm{O}_{2} / \mathrm{N}_{2}$ at Cape Grim, Tasmania. Tellus B, vol. 57, 218-119.

Rodgers, K.B., O. Aumont, C. Menkes. and T. Gorgues, submitted. Decadal variations in equatorial Pacific ecosystems and ferrocline/pycnocline decoupling. (Global Biogeochem. Cycles).

Sarmiento, J. L., N. Gruber, M. A. Brzezinski, and J. P. Dunne, 2004. High latitude controls of the global nutricline and low latitude biological productivity. Nature, 427: 56-60.

Sarmiento, J. L., R. D. Slater, M. E. Maltrud, A. Gnanadesikan, and J. Dunne, in preparation-a. Iron fertilization models revisited.

Sarmiento, J. L., J. Simeon, and A. Gnanadesikan, in preparation-b. Sub-Antarctic Mode Water pathways and nutrients.

\section{Additional References Discussed in Report}

Aksnes, D.L., and J.K. Egge. 1991. A theoretical model for nutrient uptake in phytoplankton. Marine Ecology Progress Series 70:65-72.

Armstrong, R.A. 2003a. A hybrid spectral representation of phytoplankton growth and zooplankton response: The "control rod" model of plankton interaction. Deep-Sea Research II 50:2895-2916.

Armstrong, R.A. 2003b. Representing biogeochemical diversity and size spectra in ecosystem models of the ocean carbon cycle. In: Canham, C.D., J.J. Cole, and W.K. Laurenroth (Eds.), Models in ecosystem science. Princeton University Press, Princeton, NJ, pp. 254-271.

Dutkiewicz, S., M. J. Follows, P. Heimbach, and J. Marshall (2006), Controls on ocean productivity and air-sea carbon flux: An adjoint model sensitivity study, Geophysical Research Letters, 33, L02603, doi:10.1029/2005GL024987.

Geider, R.J., H.L. MacIntyre, and T.M. Kana. 1996. A dynamic model of photoadaptation in phytoplankton. Limnology and Oceanography 41:1-15.

Geider, R.J., H.L. MacIntyre, and T.M. Kana. 1998. A dynamic regulatory model of phytoplanktonic acclimation to light, nutrients, and temperature. Limnology and Oceanography 43:679-694.

Laws, E.A., and T.T. Bannister. 1980. Nutrient- and light-limited growth of Thalassiosira fluviatilis in continuous culture, with implications for phytoplankton growth in the ocean. Limnology and Oceanography 25:457-473.

Laws, E.A., and T.T. Bannister. 2004. Erratum: Nutrient- and light-limited growth of Thalassiosira fluviatilis in continuous culture, with implications for phytoplankton growth in the ocean. Limnology and Oceanography 49:2316. 
Moore, J.K., S.C. Doney, D.M. Glover, and I.Y. Fung. 2002b. Iron cycling and nutient-limitation patterns in surface waters of the world ocean. Deep-Sea Research II 49:463-507.

Moore, J.K., S.C. Doney, J.A. Kleypas, D.M. Glover, and I.Y. Fung. 2002a. An intermediate complexity marine ecosystem model for the global domain. Deep-Sea Research II 49:403462.

Munk, W.H., and G.A. Riley. 1952. Absorbtion of nutrients by aquatic plants. Journal of Marine Research 11:215-240.

Pasciak, W.J., and J. Gavis. 1974. Transport limitation of nutrient uptake in phytoplankton. Limnology and Oceanography 19:881-888.

Pasciak, W.J., and J. Gavis. 1975. Transport limited nutrient uptake rates in Ditylum brightwellii. Limnology and Oceanography 20:604-617.

Sarmiento, J. L., and J. C. Orr (1991), Three-dimensional simulations of the impact of Southern Ocean nutrient depletion on atmospheric CO2 and ocean chemistry, Limnology and Oceanography, 36, 1928-1950.

Sunda, W.G., and S.A. Huntsman. 1997. Interrelated influence of iron, light, and cell size on marine phytoplankton growth. Nature 390:389-392.

Totterdell, I.J., R.A. Armstrong, H. Drange, J.S. Parslow, T.M. Powell, and A.H. Taylor. 1993. Trophic resolution. In: Evans, G.T., and M.J.R. Fasham (Eds.), Towards a model of ocean biogeochemical processes. Springer-Verlag, New York, pp. 71-92. 
Appendix 1

Final Report for first grant period from September 1, 2007 to November 30, 2003 


\title{
Ocean carbon sequestration by fertilization: An integrated biogeochemical assessment
}

\author{
Grant DE-FG02-00ER63009 \\ DOE Office of Biological and Environmental Research
}

FINAL REPORT

PRINCETON UNIVERSITY

Jorge L. Sarmiento, PI

Anand Gnandesikan, Co-PI

UNIVERSITY OF CALIFORNIA, LOS ANGLES

Nicholas Gruber, PI

\section{Overview}

This final report summarizes research undertaken collaboratively between Princeton University, the NOAA Geophysical Fluid Dynamics Laboratory on the Princeton University campus, the State University of New York at Stony Brook, and the University of California, Los Angeles from 09/01/2000 to 08/31/2003 sponsored by DOE's and entitled “Ocean carbon sequestration by fertilization: An integrated biogeochemical assessment”.

Under this grant, we investigated a range of issues associated with the proposal to fertilize the ocean with nutrients (such as iron) in order to increase the export of organic matter from the ocean's near surface waters and consequently increase the uptake of $\mathrm{CO}_{2}$ from the atmosphere. There are several critical scientific questions that have the potential to be make-orbreak issues for this proposed carbon sequestration mechanism:

(6) If iron is added to the ocean, will export of organic carbon from the surface actually occur? Clearly, if no export occurs, then there will be no sequestration.

(7) If iron fertilization does lead to export of organic carbon from the surface of the ocean, how much $\mathrm{CO}_{2}$ will actually be removed from the atmosphere? Even if carbon is removed from the surface of the ocean, this does not guarantee that there will be significant removal of $\mathrm{CO}_{2}$ from the atmosphere, since the $\mathrm{CO}_{2}$ may be supplied by a realignment of dissolved inorganic carbon within the ocean.

(8) What is the time scale of any sequestration that occurs? If sequestered $\mathrm{CO}_{2}$ returns to the atmosphere on a relatively short time scale, iron fertilization will not contribute significantly to slowing the growth of atmospheric $\mathrm{CO}_{2}$.

(9) Can the magnitude of sequestration be verified? If verification is extremely difficult or impossible, this option is likely to be viewed less favorably.

(10) What unintended consequences might there be from fertilizing the ocean with iron? If these are severe enough, they will have a significant impact on policy decisions. Most research on carbon sequestration by fertilization has focused on the first of these issues. Although a number of in situ fertilization experiments have successfully demonstrated that the 
addition of iron leads to a dramatic increase in ocean productivity, the question of whether this results in enhanced export remains an open one. The primary focus of our research was on the development of models to examine topics (2) through (5), although some of the research we accomplished has implications for the first of these topics as well. In the following we present and discuss our main results and products.

We start with a discussion of our results from large-scale fertilization experiments using a relatively simple ecosystem model. While these experiments are very instructive in highlighting the mechanisms and consequences, it is very unlikely that fertilization will ever be carried out on such scales. We therefore conducted a detailed study to investigate how patch-scale fertilization differs from that conducted at basin scale. After presenting the results of this study, we then discuss the results we obtained with regard to consequences of fertilization on ocean biogeochemistry and radiative forcing. Since the existing ecological/biogeochemical models at the beginning of our grant were not adequate to investigate many important components of how ocean ecology and biogeochemistry will respond to the addition of iron, a substantial fraction of our efforts went also into the development of a model that would allow us to quantitatively predict phytoplankton functional group diversity. After reporting on our model development work, we close with a summary of our outreach activities and publications.

Note: Publications supported by this grant are identified by italics.

\section{Large Scale Fertilization}

When we began this project, we were thinking almost exclusively in terms of long-term fertilization over large regions of the ocean such as the Southern Ocean, with much of our concern being on how the ocean circulation would control the response to a given fertilization scenario. Early on in our project, it became clear that small "patch-scale" fertilizations over limited regions of order $100 \mathrm{~km}$ diameter were much more likely. We describe here the largescale fertilization simulations we carried out, and discuss patch scale fertilization simulations in the following section.

We assumed that iron addition is able to cause macronutrient depletion and applied such depletion over different basins in a set of model simulations (Marinov et al., in prep.-b). Because of the circulation characteristics and large concentration of unused surface nutrients in the Southern Ocean, depleting nutrients in this area results in much higher atmospheric $\mathrm{CO}_{2}$ drawdown than depleting nutrients in the North Atlantic, North Pacific, or tropical ocean, confirming earlier work on this problem (Sarmiento \& Orr, 1991).

Based on four sets of simulations, in which isopycnal and diapycnal diffusivity coefficients were varied in the tracer equations (Gnanadesikan et al., submitted), resulting in very different circulation scenarios, we found that depleting nutrients results in similar sequestration of $\mathrm{CO}_{2}$ despite large variations in the productivity and nutrient profiles (Marinov et al., 2003, in prep.-a). This surprising result is due in part to how the rest of the ocean responds to Southern Ocean fertilization. Complete removal of macronutrients in this region results in the removal of the performed nutrients that are usually transported into the low latitudes (Sarmiento 
et al., in press). As a consequence the nutrient levels throughout the upper ocean are reduced, causing low latitude productivity to plummet (Sarmiento et al., in press). In the case of a model that has low vertical mixing, low latitude productivity decreases by about 75\% (Marinov et al., in prep.-b; Sarmiento et al., in press). This effect extends all the way to the North Atlantic, the other major source of deep water production, reducing surface nutrients in this region as well. Thus depleting the Southern Ocean enhances the efficiency of nutrient removal by the biological pump throughout the global ocean (though at the cost of remote reduction in productivity). Models with elevated vertical mixing show a larger local response in the Southern Ocean but a weaker remote response in the rest of the global ocean so that the total effect is very similar. .

In order to understand what areas of the Southern ocean are responsible for most of the $\mathrm{CO}_{2}$ uptake with depletion, we preferentially depleted the Southern Ocean only in areas with densities larger than sigma theta $=27.1,27.3,27.5$, and 27.6, respectively (Marinov et al., in prep.-b). Depleting Southern Ocean areas with densities larger than sigma theta=27.1 (roughly south of $55^{\circ} \mathrm{S}$ ) results in a $65.5 \mathrm{ppm}$ drawdown in atmospheric $\mathrm{CO}_{2}$. This accounts for most of the $73 \mathrm{ppm}$ resulting from the depletion of the Southern ocean south of $30^{\circ} \mathrm{S}$. Interestingly, convection centers covering a relatively small fraction of this region prove to be a major player in the response to depletion, accounting for the majority of the Southern Ocean uptake of $\mathrm{CO}_{2}$ following fertilization.

\section{Patch fertilization}

We performed simulations to examine the impact of fertilizing small patches of ocean (a few hundred kilometers on a side) to sequester carbon dioxide (Gnanadesikan et al., 2003). We found that less than $10 \%$ of the increased export from a one-month fertilization event came from the atmosphere after 100 years. This efficiency dropped to $2 \%$ if the organic matter was remineralized in the water column rather than sinking all the way to the sediment water interface. Verification of this removal is likely to pose a major challenge as the resulting air-sea fluxes are well below our ability to detect them in the ocean, and the time and space scales involved are very long. A way to enhance the response is to add macronutrients at the same time as iron. If the added iron is retained in the water column with the micronutrients upon remineralization, the efficiency of the fertilization increases to $40 \%$. However, biogeochemists do not have a very good understanding yet of whether the added iron would in fact be retained or scavenged by sinking particles and deposited into the sediments.

We found that patch fertilization without macronutrient addition will reduce biological productivity because it removes nutrients from the upper ocean. The impact of this can be quite large, with the worst-case scenario giving a 30-ton reduction in productivity for every 1-ton of carbon removed from the atmosphere. In the following section, we discuss additional work that we did on the impact of patch as well as large-scale fertilization on the nitrous oxide concentration in the atmosphere.

We also found that there can be a strong dependence of efficiency on the way that biology is parameterized in the model, including the remineralization profile. The biological model that we used in our patch fertilization scenarios is a simple "diagnostic" model such as that described in a later section. During the period of this grant, we made considerable progress 
on the background work required to develop a more realistic model. With the renewal of this grant, we are now in the final stages of implementing this model and will use it to re-examine the patch fertilization scenarios.

\section{Biogeochemical Consequences of Fertilization}

The expected increase in the export of organic material from the surface ocean into the interior as a consequence of a successful fertilization will result in enhanced rates of remineralization in the deeper layers of the ocean. Fuhrman and Capone (1991) pointed out that such an increase in remineralization will likely enhance production of nitrous oxide, that, when emitted into the atmosphere, will result in some offset of the radiative benefit of the atmospheric $\mathrm{CO}_{2}$ reduction stemming from the fertilization. This potential feedback is particularly worthwhile investigating since $\mathrm{N}_{2} \mathrm{O}$ is 200 times more radiatively active than $\mathrm{CO}_{2}$.

We investigated the consequences of iron fertilization on oceanic $\mathrm{N}_{2} \mathrm{O}$ emissions with our diagnostic biological model, to which we added a simple description of the $\mathrm{N}_{2} \mathrm{O}$ cycle following Suntharalingam (1997) (Jin and Gruber, in press). We separately considered the nitrification and low oxygen mechanisms that are known to produce $\mathrm{N}_{2} \mathrm{O}$. As the relative role of these processes are not well known, we set up two simulations, one considering the nitrification pathway only and the second considering the low oxygen pathway only. As the tracer equation is linear we can combine the results of these extreme cases to obtain any intermediate case. Our "best estimate" case is that which assumes that about half of the global oceanic production of $\mathrm{N}_{2} \mathrm{O}$ comes from the nitrification pathway, and the other half from the low oxygen pathway. This best estimate is based on the studies of Suntharalingam and Sarmiento (2000) and our own extensive comparison of our model results with in situ data (Jin and Gruber, in prep). We conducted large-scale and patch fertilization experiments in the tropics, the Southern Ocean, the Northern North Pacific Ocean and the Northern North Atlantic Ocean. We further considered a fertilization of 10 year duration, followed by 90 years without fertilization and a fertilization of 100 year duration.

We found that the magnitude of the warming offset caused by nitrous oxide release to the atmosphere is substantial, but is highly dependent on the location and duration of fertilization (Jin and Gruber, in press). The largest offset (of the order of 100\%) is found when fertilization is undertaken in the tropics, particularly when it is of limited duration and size. Smaller, but still substantial effects are found when fertilization is undertaken elsewhere and over longer periods. These results suggest that any assessment of ocean fertilization as a mitigating option is incomplete without consideration of the $\mathrm{N}_{2} \mathrm{O}$ feedback.

The oceanic oxygen concentrations play a key role in controlling the magnitude of the $\mathrm{N}_{2} \mathrm{O}$ feedback, due to the very high $\mathrm{N}_{2} \mathrm{O}$ yields occurring at low oxygen concentrations (Jin and Gruber, in prep). The low oxygen concentration found in the thermocline of the tropical ocean makes this region the most sensitive one with regard to the magnitude of the $\mathrm{N}_{2} \mathrm{O}$ feedback. The substantial reduction of the thermocline oxygen concentration in the North Pacific as a result of the long-term fertilization turns this region from one whose $\mathrm{N}_{2} \mathrm{O}$ formation mechanism is dominated by the nitrification pathway to one dominated by the denitrification pathway, highlighting the non-linear response of the system. 
As discussed above for the Southern Ocean, a second important consequence of iron fertilization is the decrease of primary production in regions outside those that are fertilized (Gnanadesikan et al., 2003; Sarmiento et al, in press; Marinov et al., in prep-b). Interestingly, this decrease is another reason why the magnitude of the $\mathrm{N}_{2} \mathrm{O}$ feedback is smallest in the Southern Ocean, as this decrease in the low latitude production actually reduces the $\mathrm{N}_{2} \mathrm{O}$ production in the low latitudes, where yields tend to be high, leading to quite a substantial offset in the increased $\mathrm{N}_{2} \mathrm{O}$ production in the Southern Ocean (Jin and Gruber, in press).

\section{Model Development}

The existing ocean biogeochemistry/ecology models at the onset of this project were insufficient to address many of the detailed questions associated with the role of upper ocean ecosystem structure in determining the response of the ocean to nutrient fertilization. In particular, we suggested that the oceanic response to iron fertilization would depend very strongly on the specific response of the main phytoplankton functional groups. For example, the impact of increased productivity on the air-sea balance of $\mathrm{CO}_{2}$ would depend on the relative ratio of organisms that produce $\mathrm{CaCO}_{3}$ shells (hypothesized to be due mainly to coccolithophorids) and those that just produce organic matter. The most important group of species in the latter group are diatoms, which require silicic acid to grow. Since the formation of $\mathrm{CaCO}_{3}$ increases the partial pressure of $\mathrm{CO}_{2}$, a replacement of coccolithophorids by diatoms or some other phytoplankton while keeping export production the same would lead to a sequestration of $\mathrm{CO}_{2}$ from the atmosphere. We have proposed such a mechanism to explain in part the observed change in atmospheric $\mathrm{CO}_{2}$ between the last glacial maximum and today (Brzezinski et al, 2002; Matsumoto et al., 2002), but an assessment of the impact of such changes in ecology on humanscale ocean iron fertilization requires a detailed predictive model that includes such phytoplankton functional group diversity explicitly. No such model existed at the onset of our project. We proposed to develop such a model in three stages.:

- A diagnostic biogeochemical model, in which all the nutrients and alkalinity are forced towards the observed fields at the surface of the ocean.

- A semi-prognostic biogeochemical model, in which only phosphate is forced towards observations at the surface of the ocean, and export is predicted by a set of ecological rules.

- A fully prognostic model, which explicitly models phytoplankton dynamics through light and nutrient limitation.

We made considerable progress on all three of these modeling approaches and discuss each of them in turn. With the renewal of this grant, we are now in the final stages of implementing these models and will use them for a new set of fertilization scenarios that we expect will settle many of the issues that were raised by our earlier studies.

\section{1.)Diagnostic biogeochemistry}

In this model, we infer biological productivity from the physical supply of nutrients through the mismatch between modeled and observed surface nutrient fields. By separately modeling nitrate, phosphate, silicate, alkalinity and iron, we infer the stoichiometry of elemental fluxes. Previous runs done at Princeton have had a very simple relationship between production and export. We have developed a new diagnostic model of biogeochemical cycling which takes 
advantage of the large amount of data collected during the past decade relating primary production to export, as well as distributions of dissolved organic matter (cf., Jin et al., in prep.). This model starts by restoring surface phosphate towards observations and then uses a simple ecosystem (Dunne et al, submitted, $G B C$ ) to allocate the diagnosed total production to small and large phytoplankton). Phosphorus surplus is used to diagnose nitrogen fixation in the surface while anoxic remineralization is used to diagnose denitrification in the interior (Deutsch 2003). The contribution of diatoms and coccolithophorids to the large phytoplankton production is determined by converting the diagnostically inferred opal and $\mathrm{CaCO}_{3}$ productions into organic nitrogen production. This model allows us to infer the partitioning of organic productivity into sinking material, regenerated nutrients and dissolved organic material and compare our estimates of productivity with satellite observations of ocean color (Dunne et al., 2002, Eos Trans.).

We have coupled the cycling of particulate organic material in the water column to that of silicon and alkalinity through the inclusion of the protection of sinking organic material by opal and calcium carbonate ballast, allowing us to reproduce the global constancy in the carbon content in sinking material collected in deep sediment traps (Dunne et al., in prep.-b). Our preliminary results show a global organic carbon production of $13.9 \mathrm{Pg} \mathrm{C} / \mathrm{yr}, \mathrm{a} \mathrm{CaCO}_{3}$ production of $1.16 \mathrm{Pg} \mathrm{C} / \mathrm{yr}$ and an opal production of $188 \mathrm{~T} \mathrm{~mol} \mathrm{Si/yr}$. The implied export ratios of inorganic carbon to organic carbon are about $0.08: 1$, consistent with the vertical ratio analysis of Sarmiento et al. (2002) (see below). Small phytoplankton are found to dominate, with more than $75 \%$ of global production associated with this functional group. Their dominance is particularly strong in the low latitudes. Among the large phytoplankton, the diatoms, coccolithophorids and other large phytoplankton contribute roughly equally to NPP. As expected, diatoms tend to dominate at high latitudes, where they make up more than $40 \%$ of the large phytoplankton production. Equatorward of the diatom-dominated belt, coccolithophorids are dominant. A paper on this topic is currently in preparation (Jin et al., in prep.).

In our attempt to characterize the cycling of dissolved organic matter, we found the inclusion of differential production or regeneration of dissolved organic material (DOM) critical in reproducing observed meridional trends. Specifically, production in the oligotrophic regions of DOM was inferred to be either a much larger fraction of the total production, or much longerlived. We are using new support to continue experimenting with various mechanistic formulations of the sinking detrital pool to investigate controls on remineralization in the ocean interior including such effects as the protection of organic material by mineral ballast, temperature, lability, sinking velocity and zooplankton grazing (Dunne et al., in preb.-b).

\section{2.)Semi-prognostic biogeochemistry}

We developed a first version of this model, but put this project on hold until we could complete analysis of the diagnostic model to develop an improved model for prediction of stoichiometric ratios. A specific result from this study was the necessity for including variable $\mathrm{Si}: \mathrm{N}$ ratios in any prognostic model. In particular, unless we simulate the unusually high Si:N drawdown ratios of Southern Ocean iron limited production, we predict excessive silicic acid concentrations in low latitudes and an unrealistic domination of diatoms at all latitudes (cf., Brzezinski et al., 2002; Matsumoto et al. 2002; Sarmiento et al., in press).

\section{3.)Prognostic model development}

The prognostic version of the model, which we expect to complete by early next year 
with the renewal of this grant, builds on the two previous models by incorporating explicit phytoplankton growth with a simple light penetration model. It includes three phytoplankton groups: small (patterned after cyanobacteria with coccolithophorids also included as a fixed fraction of the small phytoplankton), large (patterned after diatoms) and diazotrophic (patterned after trichodesmium) (Dunne et al., submitted). Phytoplankton growth rates are determined as a function of temperature, light and nutrient limitation as well the $\mathrm{C}$ :Chl ratio in phytoplankton which is allowed to vary instantaneously after the Geider et al. (1996) model of equilibrium carbon and nutrient uptake. Nutrient limitation is expressed using Liebig's law of the minimum by nitrate, ammonia, phosphate, silicate and iron. Nitrogen limitation includes ammonia inhibition and nitrogen fixation by diazotrophs. The export and remineralization parameterizations developed with the diagnostic model (cf., Dunne et al., submitted, and Dunne et al., in prep.-b) are implemented to predict the export and fate of organic matter.

\section{Analyses of Observations and Models}

As part of our efforts to develop improved models of ocean ecology and to test those models, we did several combined model-data analysis studies of how export from the surface of the ocean is related to the primary production, and what the $\mathrm{CaCO}_{3}$ and diatom opal to organic carbon export ratios are around the world. The response of the ocean to a fertilization event will depend greatly on the nature of the organisms that carry out the enhanced production, and their ability to export organic matter from the surface of the ocean. The information gained from these studies provided major insights that were or are being incorporated into our models.

\section{1.)Particle export ratio}

Iron fertilization experiments in waters with unutilized nutrient have unfailingly shown an increase in primary production, yet have failed so far to clearly demonstrate an increase in export (Nodder and Waite, 2001). Is this a result of incomplete observations, or are there reasons to expect that the additionally fixed nutrients merely cycle more rapidly within the mixed layer? This question can be cast in terms of the pe-ratio, the ratio of particulate export to primary production.

We have synthesized observations of the particle export ratio and used this synthesis to calibrate empirical algorithms of the particle export ratio as a function of the log of biomass (or productivity) and temperature (Dunne et al., submitted, $G B C$ ). We also developed a predictive, ecosystem-based model of the pe-ratio as it varies in space and time through temperature, and productivity through changes in phytoplankton size structure and mineral ballast protection of sinking detritus. The model is driven by the difference in the functional form of the grazing loss term and export efficiencies between large phytoplankton (where grazing is proportional to the four-thirds power of efficiently-exported biomass) and small phytoplankton (where grazing is proportional to the second power of inefficiently-exported biomass). We demonstrate that both the empirical regression and the simple ecosystem size-based model reproduce the observed variability in pe-ratios (Dunne et al., submitted).

This simple ecosystem model has been implemented within the diagnostic ocean biogeochemistry model described in the previous section. This model is able to reproduce major patterns in primary production as interpreted from satellite-based estimates of ocean color, 
surface irradiance, temperature and euphotic zone depth. Important differences exist, however, which point to deficiencies in the model's representation of ocean circulation, our biological representation of ocean ecosystems, and the satellite chlorophyll and primary productivity algorithms.

\section{2.)A new estimate of the $\mathrm{CaCO}_{3}$ to organic carbon export ratio}

We used an ocean biogeochemical-transport box model of the top $200 \mathrm{~m}$ of the water column to estimate the $\mathrm{CaCO}_{3}$ to organic carbon export ratio from observations of the vertical gradients of potential alkalinity and nitrate (Sarmiento et al., 2002). We found a global average molar export ratio of $0.06+/-0.03$. This is substantially smaller than earlier estimates of 0.25 on which a majority of ocean biogeochemical models had based their parameterization of $\mathrm{CaCO}_{3}$ production. Contrary to the pattern of coccolithophore blooms determined from satellite observations, which show high latitude predominance, we found maximum export ratios in the equatorial region and generally smaller ratios in the subtropical and subpolar gyres. Our results suggest a dominant contribution to global calcification by low-latitude non-bloom forming coccolithophores or other organisms such as foraminifera and pteropods.

\section{3.)A new estimate of the opal to organic carbon export ratio}

We used the same box model employed for estimating the $\mathrm{CaCO}_{3}$ to organic carbon export ratio (see above) to estimate the opal to organic nitrogen (and thereby, carbon) export ratio from observations of the vertical gradients of silicic acid and nitrate (Sarmiento et al., in press). This study shows that the Southern Ocean has exceptionally high export ratios that result in a complete depletion of silicic acid in waters that are still rich in nitrate. The export of this water to the north explains the low concentration of silicic acid in much of the rest of the world. Including this in models is essential to correctly simulating diatom production, as noted previously.

4.)A new estimate of global particle export and remineralization of the major elements

We have used our particle export ratio estimates in combination with satellite based estimates of primary production to calculate export production of organic carbon in the world ocean. These export production maps have been used to test our model simulations (Gnanadesikan, et al., submitted). The box model method that we employed to estimate the $\mathrm{CaCO}_{3}$ and opal to organic carbon export ratios can also be used to estimate the export ratios of the other macronutrients (nitrogen and phosphorus). Combining the organic carbon export production maps with our export ratio estimates makes it possible to provide a new set of global estimates of the particle export of all the major nutrients. We can also use the remineralization functions to estimate the cycling of this exported organic matter in the ocean interior. We are presently writing a paper describing the results of this analysis (Dunne et al., in prep.-a), and will continue to use the results of these types of analyses to test and improve our ocean biogeochemistry models for predicting the response to fertilization.

\section{Outreach}

During the period of this grant, we wrote a series of overview papers related to the carbon cycle of the ocean that were informed by the research that was carried out as part of this project, although they do not explicitly acknowledge any specific grant. These include: Edmonds et al., 
in press, Gruber et al, in press, Marinov et al. in press, and Sarmiento and Gruber (2002).

\section{Summary}

In concluding, we return to the set of five questions we raised in the introductory overview and use these as a template to summarize the major findings of our research with relevance to the use of fertilization to sequester $\mathrm{CO}_{2}$ from the atmosphere.

(1) If iron is added to the ocean, will export of organic carbon from the surface actually occur?

Ultimately, this question must be answered by in situ experiments. However, our empirical work on the relationship between particle export and primary production (Dunne et al., submitted) is certainly consistent with the general expectation that the increased primary production that has been observed in iron fertilization studies should result in increased export.

(2) If iron fertilization does lead to export of organic carbon from the surface of the ocean, how much $\mathrm{CO}_{2}$ will actually be removed from the atmosphere?

Our short-term patch-fertilization scenarios (Gnanadesikan et al., 2003) suggest that the efficiency of small-scale iron fertilization scenarios, i.e., the fraction of increased export production that comes from the atmosphere, is likely to be extremely low (2-10\% after 100 years). This low efficiency can go as high as $40 \%$ after 100 years, but only if macronutrients (nitrate and phosphate) are added with the iron and if the iron is retained in the water column rather than scavenged. Long-term basin-scale fertilization scenarios are more efficient in preventing the carbon from escaping back to the atmosphere.

An important caveat is that the biogeochemistry model that was used for these simulations is an extremely simple diagnostic model based on forcing surface nutrients back towards observations, or to 0 in the case of the nutrient depletion scenarios. We did not include functional groups in this model, and our modeling of the iron distribution and interior remineralization of organic matter was also rudimentary. A critical issue that remains to be addressed is how our conclusions would be affected if we used a more realistic biogeochemistry model such as we developed as part of this grant (cf., Deutsch, 2003, Dunne et al., submitted, Gnanadesikan et al., submitted, and Dunne et al., in prep.-b). Ongoing research with a renewal of this grant should enable us to implement our new biogeochemistry model and address these issues in the near future.

(3) What is the time scale of any sequestration that occurs?

The work described under (2) shows that long-term sequestration requires long-term fertilization. A major reason for the low efficiency we found in our patch-fertilization scenarios is because of the rapid return of the sequestered carbon back to the atmosphere at locations far away from the region of fertilization.

(4) Can the magnitude of sequestration be verified? 
The short answer to this is very likely not, at least for the patch-fertilization scenarios (Gnanadesikan et al., 2003). Direct verification by measurement of the air-sea $\mathrm{CO}_{2}$ fluxes that result from a given fertilization event presents an insurmountable challenge with present technology. The fluxes are far smaller than the natural variability, and their spatial scale, particularly the longer-term escape of the sequestered $\mathrm{CO}_{2}$, is vast. Indirect verification by monitoring of the actual export of organic carbon is challenging, and inferring the impact of such an export event requires a far better understanding of what determines the efficiency of sequestration than we have at present. Verification is also extremely challenging with regard to the possible offsetting effect from $\mathrm{N}_{2} \mathrm{O}$ emissions. Jin and Gruber (in press) show that the majority of the fertilization induced outgassing of $\mathrm{N}_{2} \mathrm{O}$ into the atmosphere occurs well outside the patch and continues well into the future even after fertilization has stopped.

(5) What unintended consequences might there be from fertilizing the ocean with iron?

Our research suggests that there may be quite significant negative impacts from fertilization. In the patch-fertilization scenarios, we find a long-term reduction in biological production as nutrients are removed from the surface and sequestered at depth, unless macronutrients are added with the iron and the iron is retained in the water column (Gnanadesikan et al., 2003). Such changes in oceanic biological production are even more marked in the large-scale fertilization scenarios, where there may be as much as a 75\% reduction in global export production resulting from a Southern Ocean fertilization (Sarmiento et al., in press, and Marinov et al., in prep.-b). There is also a potentially large production of nitrous oxide, a potent greenhouse gas that may counteract much of the effect of any $\mathrm{CO}_{2}$ removal that is achieved by a given fertilization event (Jin and Gruber, in press).

\section{Students and postdoctoral researchers trained:}

- Dr. Xin Jin, Post-Doc, UCLA.

- Irina Marinov, Graduate Student, Princeton University

- Dr. Curtis Deutsch, Graduate Student, Princeton University, presently a Post-Doc at the University of Washington

- Dr. John Dunne, Post-Doc, Princeton University, presently at GFDL/NOAA

\section{Publications:}

\section{Journal and Book Articles (published, in press, and in preparation)}

Deutsch, C., 2003. Biogeochemical constraints on the modern and glacial oceanic nitrogen cycle. Ph.D. Thesis, Princeton University, Princeton, NJ.

Dunne, J. P., R. A. Armstrong, A. Gnanadesikan, J. L. Sarmiento, and R. D. Slater (in preparation-a) New estimates of global particle export of the major elements and their cycling in the ocean interior. (Global Biogeochem. Cycles)

Dunne, J. P., R. A. Armstrong, A. Gnanadesikan, J. L. Sarmiento, and R. D. Slater, submitted. Empirical and mechanistic models for particle export ratio. (Global Biogeochem. Cycles)

Dunne, J. P., A. Gnanadesikan, P. Swathi, J. L. Sarmiento and R. Armstrong (in preparation-b) Controls on global particle export and remineralization in a global ocean general circulation model, (Global Biogeochemical Cycles)

Edmonds, J., F. Joos, N. Nakicenovic, R. Richels, and J. L. Sarmiento, in press. Scenarios, 
targets, gaps, and costs. In: Toward CO2 Stabilization: Issues, Strategies, and Consequences, A SCOPE/GCP Rapid Assessment Project, ed. C. Field and M. Raupach, Island Press, Washington, D.C.

Gnanadesikan, A., J. P. Dunne, R. M. Key, K. Matsumoto, J. L. Sarmiento, R. D. Slater, and P,. S. Swathi, submitted. Oceanic vertical exchange and biogeochemical cycling: Comparisons between models and new observational estimates. (Global Biogeochem. Cycles)

Gnanadesikan, A., J. L. Sarmiento, and R. D. Slater, 2003. Effects of patchy ocean fertilization on atmospheric carbon dioxide and biological production. Global Biogeochem. Cycles, 17 (2), doi: 10.1029/2002GB001940.

Gruber, N., P. Friedlingstein, C.B. Field, R. Valentini, M. Heimann, J.E. Richey, P. RomeroLankao, D. Schulze, and C.-T.A. Chen, in press. The vulnerability of the carbon cycle in the 21st century: An assessment of carbon-climate-human interactions, In: Toward $\mathrm{CO}_{2}$ Stabilization: Issues, Strategies, and Consequences ,Eds: C. B. Field and M. R. Raupach, Island Press.

Jin, X., J. Dunne, C. Deutsch and N. Gruber, in prep., Diagnosing phytoplankton functional groups from global nutrient and alkalinity distributions. (Global Biogeochemical Cycles)

Jin, X. and N. Gruber, in prep. Constraining oceanic $\mathrm{N}_{2} \mathrm{O}$ production mechanisms by an inversion of large-scale oceanic $\mathrm{N}_{2} \mathrm{O}$ data. (Global Biogeochemical Cycles)

Jin, X. and N. Gruber, in press. Offsetting the radiative benefit of ocean iron fertilization by enhancing $\mathrm{N} 2 \mathrm{O}$ emissions (Geophys. Res. Lett.)

Marinov, I., A. Gnanadesikan, J.L. Sarmiento and R.D. Slater, in preparation-a, What controls the air-sea flux of carbon dioxide? (Global Biogeochem. Cycles.)

Marinov, I., and J. L. Sarmiento, in press. The role of the oceans in the global carbon cycle: An overview. In: Ocean Carbon Cycle and Climate, ed. M. Follows and T. Oguz, NATO ASI, Ankara, Turkey.

Marinov, I., J.R. Toggweiler, A. Gnanadesikan, K. Matsumoto, J.L. Sarmiento and R.D. Slater, in preparation-b, Impacts of nutrient depletion in general circulation models and box models. (Global Biogeochem. Cycles)

Sarmiento, J. L., J. Dunne, A. Gnanadesikan, R. M. Key, K. Matsumoto, and R. Slater, 2002. A new estimate of the $\mathrm{CaCO}_{3}$ to organic carbon export ratio. Global Biogeochem. Cycles, 16 (4), 1107, doi:10.1029/2002GB001919.

Sarmiento, J.L., and N. Gruber, 2002. Sinks for anthropogenic carbon, Physics Today, August 2002, pp 30-36.

Sarmiento, J. L., N. Gruber, M. A. Brzezinski, and J. P. Dunne, in press. High latitude controls of the global nutricline and low latitude biological productivity. (Nature).

Conference Abstracts:

Dunne, J.P., R. A. Armstrong, C. Deutsch, A. Gnanadesikan, J.L. Sarmiento, 2002. A multielement ecosystem model for global biogeochemical cycles, Eos Trans. AGU, 83(4), Ocean Sci. Meet. Suppl., Abstract OS32L-12.

Gnanadesikan, A., J.L. Sarmiento, and R.D. Slater, 2001. Ocean fertilization and biological productivity, Proceedings, 1st National Conference on Carbon Sequestration, National Energy Technology Laboratory, Paper 6D-1.

Gnanadesikan, A., J.L. Sarmiento and R.D. Slater, 2002. Changes in atmospheric carbon dioxide and biological productivity induced by patchy fertilization, Eos Trans. AGU, 83(4), Ocean Sci. Meet. Suppl., Abstract OS51F-08. 
Gnanadesikan, A., J.L. Sarmiento and R.D. Slater, 2002. Efficiency and effects of carbon sequestration through ocean fertilization, Proceedings, Sixth International Conference on Greenhouse Gas Control Technologies, Paper I3-5.

Jin, X., C. Deutsch, N. Gruber, and K. Keller, 2002. Assessing the consequences of iron fertilization on oceanic N2O emissions and radiative forcing, Eos Trans. AGU, 83(4), Ocean Sci. Meet. Suppl., Abstract OS51F-10.

Jin, X. and N. Gruber, 2002. Offsetting the radiative benefit of ocean iron fertilization by enhancing ocean N2O emissions, Eos Trans. AGU, 83(47), Fall Meet. Suppl., Abstract U21A-0006.

Jin, X, N. Gruber, J.P. Dunne, and C. A. Deutsch. Diagnosing net production by the major phytoplankton functional groups from ocean nutrient and alkalinity data. Eos Trans. AGU, Ocean Sci. Meet. Suppl, in press.

Marinov, I., A. Gnanadesikan, K. Matsumoto, J.L. Sarmiento, R. D. Slater, 2002. An analysis of large-scale ocean fertilization under different circulation scenarios, Eos Trans. AGU, 83(4), Ocean Sci. Meet. Suppl., Abstract OS51F-12.

\section{Additional References Discussed in Report}

Brzezinski MA, Pride CJ, Franck VM, Sigman DM, Sarmiento JL, Matsumoto K, Gruber N, Rau $\mathrm{GH}$, Coale KH, 2002. A switch from $\mathrm{Si}(\mathrm{OH})(4)$ to NO3- depletion in the glacial Southern Ocean, Geophys. Res. Lett., 29, 10.1029/2001GL014349.

Codispoti, L.A. and J.P. Christensen, 1985. Nitrification, denitrification and nitrous oxide cycling in the Eastern Tropical South Pacific Ocean. Marine Chemistry, 16, 277-300.

Fuhrman, J.A., and D.G. Capone, 1991. Possible biogeochemical consequences of ocean fertilization. Limnol. Oceanogr. 36: 1951-1959.

Geider, R., H. MacIntyre, T. Kana, 1996. Dynamic model of phytoplankton growth and acclimiation: responses of the balanced growth rate and the chlorophyll a:carbon ratio to light, nutrient-limitation and temperature. Marine Ecological Progress Series, 148, 187-200.

Masumoto, K., J. L. Sarmiento, and M. A. Brzezinski, 2002. Silicic acid leakage from the Southern Ocean as a possible mechanism for explaining glacial atmospheric $\mathrm{pCO}_{2}$. Global Biogeochem. Cycles, 16: 10.1029/2001GB001442.

Nodder, S. D., and A. M. Waite, 2001. Is Southern Ocean organic carbon and biogenic silica export enhanced by iron-stimulated increases in biological production? Sediment trap results from SOIREE, Deep-Sea Res., II, 48, 2681-2701

Suntharalingam, P., 1997. Modeling the global oceanic nitrous oxide distribution. Ph. D. thesis, Princeton University, Princeton, NJ.

Suntharalingam, P. and J.L. Sarmiento, 2000. Factors governing the oceanic nitrous oxide distribution: Simulations with an ocean general circulation model. Global Biogeochemical Cycles, 14(1), 429-454. 